\title{
Craniopagus twins: surgical anatomy and embryology and their implications
}

\author{
J. E. A. O'CONNELL ${ }^{1}$
}

From the Department of Neurological Surgery, St. Bartholomew's Hospital, London

SYNOPSIS Craniopagus is of two types, partial and total. In the partial form the union is of limited extent, particularly as regards its depth, and separation can be expected to be followed by the survival of both children to lead normal lives. In the total form, of which three varieties can be recognized, the two brains can be regarded as lying within a single cranium and a series of gross intracranial abnormalities develops. These include deformity of the skull base, deformity and displacement of the cerebrum, and a gross circulatory abnormality. It is considered that these and other abnormalities, unlike the primary defect, which is defined, are secondary ones; explanations for them, based on anatomy and embryology, are put forward. The implications of the various anomalies are discussed and the ethical aspects of attempted separation in these major unions considered.

The birth of conjoined twins is an infrequent occurrence. Its incidence is estimated as one in 50000 births (Potter, 1961). The union is a cephalic one in $2.0 \%$ which makes the incidence of craniopagus twins one in 2.5 million births. The occurrence is thus a rarity, although, since numerous cases are not reported in the literature, it is likely that its frequency is greater than these figures indicate. Should the twins survive, the possibility of their separation will be raised with a neurosurgeon and if the union is an extensive one, as it commonly is, the problem is a daunting one. Not only is it unlikely that the surgeon will have had any previous experience of the condition, but until recent times there was little in the literature to guide him. The first report (Grossman et al., 1953) described the separation of a pair of such twins with the survival of one of them. Subsequently (O'Connell, 1964; O'Connell, 1968) came descriptions of separation operations in three cases of total vertical craniopagus, one of each pair surviving. This study of personal material has been made in the certain knowledge that further attempts to separate craniopagus twins will be made in the

\footnotetext{
- Address for reprint requests: Fishing Cottage, Itchen Abbas, near Winchester, Hampshire.
}

(Accepted 16 July 1975.) future. The practical problems resulting from disordered anatomy are discussed and their solution, complete or partial, described. The abnormal anatomy is analysed and related to embryological development. The nature of the primary congenital defect is discussed. A classification of craniopagus is produced, differentiating partial from total unions so that confusion in the literature between the different types of case may be avoided in the future. Finally, the ethical problems which arise in connection with the surgical treatment of total vertical craniopagus are discussed.

The material studied has been the records of three personally treated cases of craniopagus mentioned above and previously reported. For the present paper, certain clinical features and results of investigation as well as operative findings are reconsidered. The postmortem studies made in each of the twins of the second and third pairs who died during surgery are correlated with the other findings. In addition, through the kindness of colleagues, postmortem studies of another example of craniopagus, not seen during life, have been possible. The small but increasing literature dealing with craniopagus has been reviewed and where appropriate related to the present work. 


\section{CLASSIFICATION OF CRANIOPAGUS}

According to the site of the cephalic junction, it has been customary to classify cases of craniopagus as parietal, frontal, or occipital, over $60 \%$ of them being parietal. This method of classification is inadequate since it makes no distinction between unions of limited superficial extent and depth and the extensive unions in which the two cranial cavities are in wide connection. It is proposed that the cases be placed in two groups, partial and total. In partial craniopagus, the surface area of the heads involved is usually relatively small and the crania may be intact and simply fused in this area; or there may be a cranial defect and the dura mater of the twins be in contact and possibly fused within the defect; or the dura mater may be absent and the leptomeninges covering the related areas of cerebra are in contact with one another. The abnormality extends no deeper and is, in fact, simply a defect of cerebral coverings and frequently a limited one. It should be noted that occasionally the junction in partial craniopagus may appear to be extensive, yet radiological examination reveals that a layer of bone representing the fused skulls of the twins extends over much of the junction. Such a superficial union must, of course, be classified as partial craniopagus. In total craniopagus there is an extensive area of surface involvement and the cranial cavities are widely connected; indeed, the two brains are contained within a common cranium. This leads to the very important alterations in cerebral development and circulation which will be described later in detail. Partial craniopagus is thus essentially an extracranial abnormality and total vertical craniopagus a gross intracranial one. The partial unions may be frontal, parietal, or occipital; total craniopagus is, from its nature, likely to be biparietal and, since it is a very wide union, it is thought can better be described as vertical.

\section{Partial craniopagus}

Three pairs of twins of this type have been reported in the literature, all having been treated surgically.

The first of these (Voris et al., 1957) was a central vertical union in which the dura mater of both children was intact and a thin layer of skull separated much of the dura mater of one twin from that of the other. The result after separation was excellent in one child but the other, whose superior sagittal sinus was possibly injured at operation, has survived disabled and had repeated operations for cerebrospinal fluid fistula and ventricular dilatation (Fig. 1a). The second pair (Baldwin and Dekaban, 1958) had a frontal union (Fig. 1b); this was an oval area measuring $8.0 \mathrm{~cm} \times 6.5 \mathrm{~cm}$ and united the children's right frontal regions. There was a dural defect within this area but intact leptomeninges covered the exposed frontal cortex of each cerebrum. Separation and survival of both were achieved without defect and they were developing well seven years later. In the third pair (Wolfowitz et al., 1968), the union was also a frontal one but more localized (Fig. 1c), so that there was some mobility of one head from the other. The essential of the operative procedure was the separation of a relatively small area of dura mater of one child from a similar area in the other, and this was achieved with the survival of both children. From what follows, it will be realized that such partial unions are an entirely different problem from the total ones.

In addition to these three cases of localized craniopagus treated surgically in recent years, others must clearly have been born, if the incidence of craniopagus twins is one in twoand-a-half million births. Of a series of 22 cases (Robertson, 1953) two were frontal and five occipital. Details are not available, but it is likely that several of these were cases of the partial form. No doubt there have been other reports of cases of localized craniopagus throughout the world but the literature is not a true guide to the frequency of such abnormalities.

\section{Total craniopagus}

In this variety the union is extensive. It is commonly vertical and described in the literature as parietal. However, very widespread unions can occur elsewhere. Klar (1963) described an extensive frontal union and the author has seen radiographs of twins with an extensive parietooccipitotemporal union. In some of the reports of such extensive unions in situations other than the vertical one (Sapinski, 1966), it seems possible that the wide union was vertical at an early developmental stage. Later intrauterine forces altered the relationship of the long axes of the infants to one another so that a gross angulation occurred at the site of junction between the 


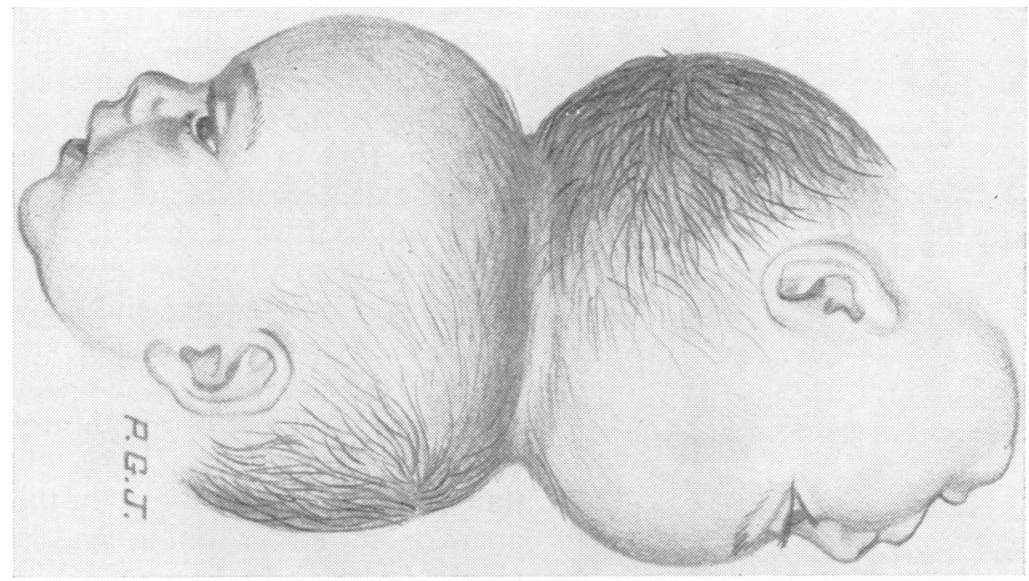

(a)

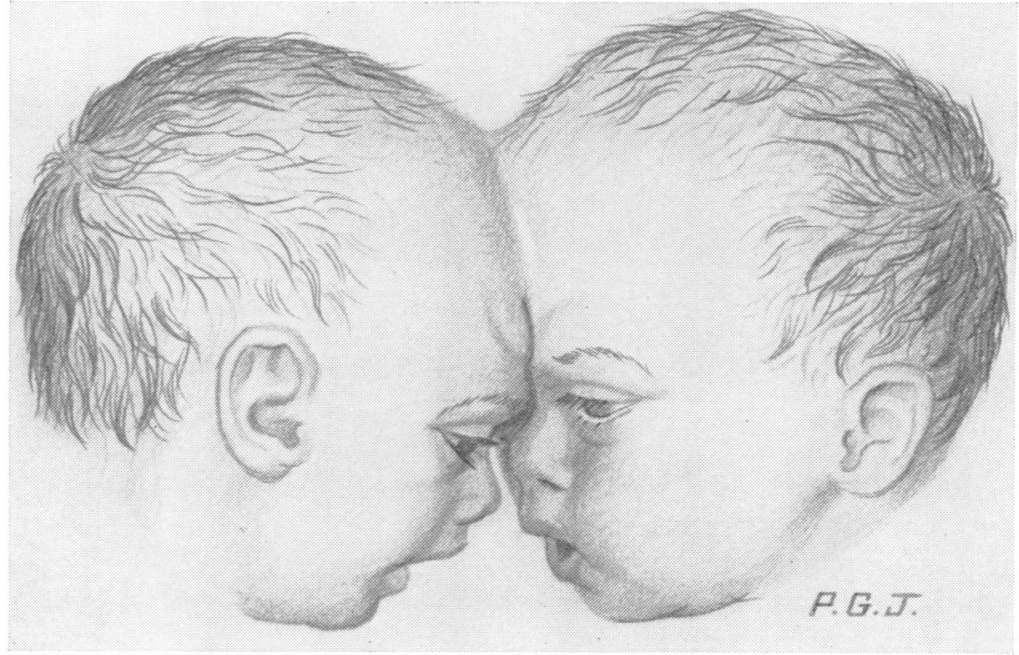

(b)

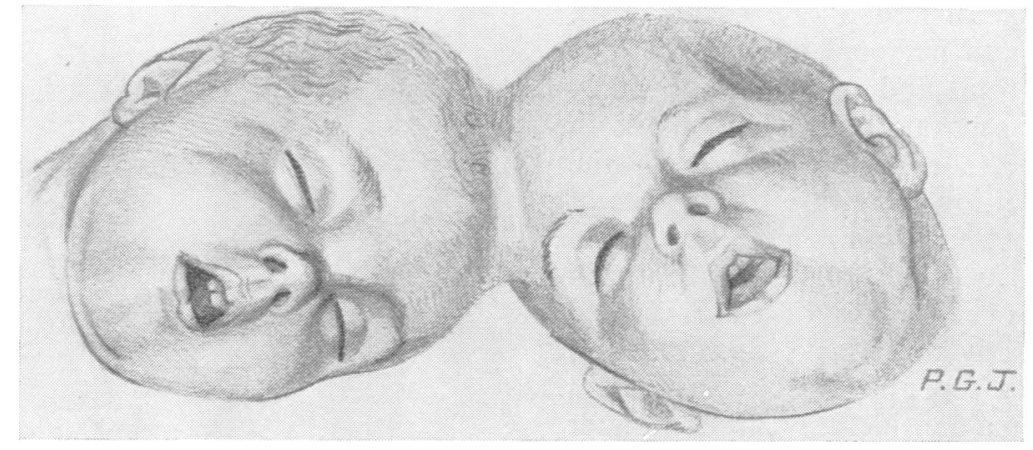

(c)

FIG. 1 Partial craniopagus: (a) Voris et al. (1957); (b) Baldwin and Dekaban (1958); (c) Wolfowitz et al. (1968). 


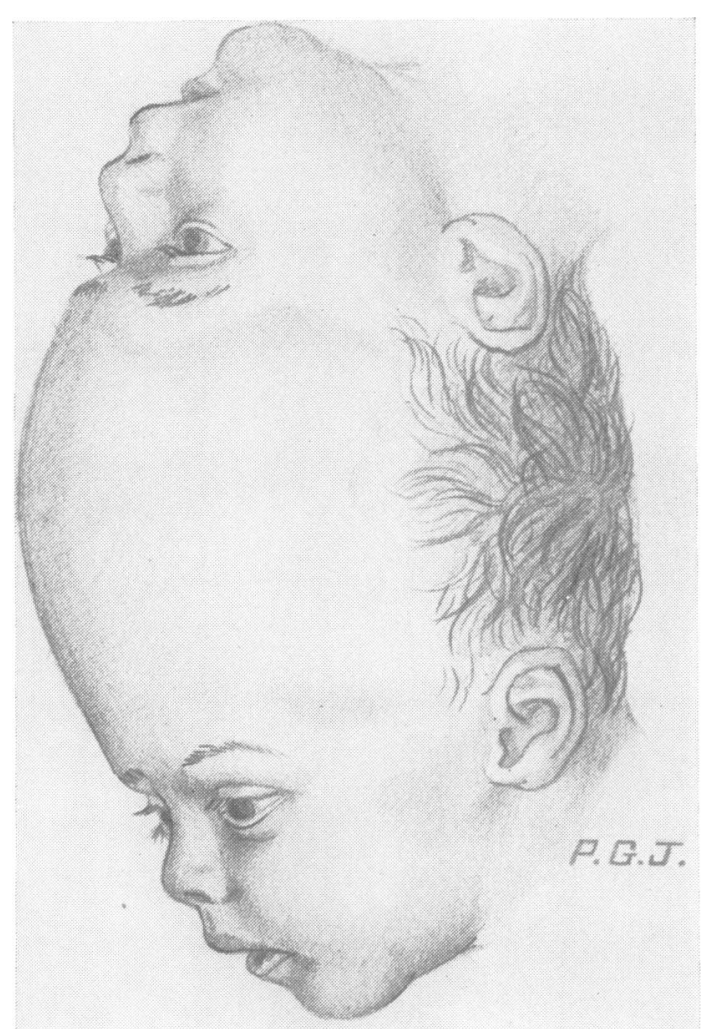

FIG. 2 Total cranioapgus: type I.

heads. The literature contains numerous references to total vertical craniopagus. Most of these deal with cases in which no attempt at separation had been made or in which, if such an attempt had been made, both children succumbed immediately. Robertson (1953) found references to 14 such cases and added one of his own. Other references and personal communications add nine to this total and of this group of 24 cases attempts at separation had been made in six but without a survivor from any of the operations. In addition, there are the reports of the four surgically treated pairs already referred to in which there was one survivor from each pair. This total of 28 cases of total vertical craniopagus certainly must lack some of those reported in the literature and it also seems certain that there has been a considerably larger number never so reported.

In total vertical craniopagus the whole vault of the skull is involved and the appearance is that of a common cranium for the two brains. Examination of personal material suggests that according to the degree of rotation of one twin's head on that of the other, around the longitudinal axis, three types of total vertical craniopagus can be distinguished. It might be expected that no such rotation would be present and that the faces of both twins would have an identical direction. However, for some reason, torsion develops in the tissues at the site of the union and varying degrees of rotation of one head on the other result. Three types of this form of union can be distinguished. In the first (type I), apart from minor tilting and rotation, both children face in the same direction (Fig. 2). In type II, the faces are on opposite sides of the

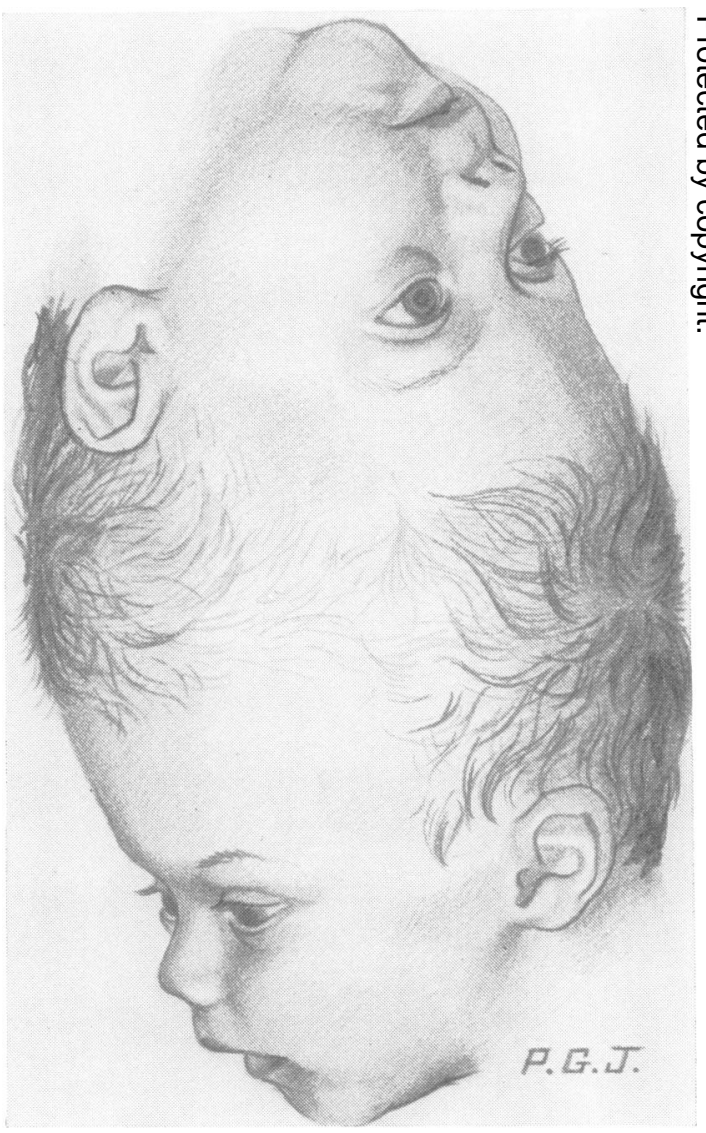

FIG. 3 Total craniopagus: type II. 


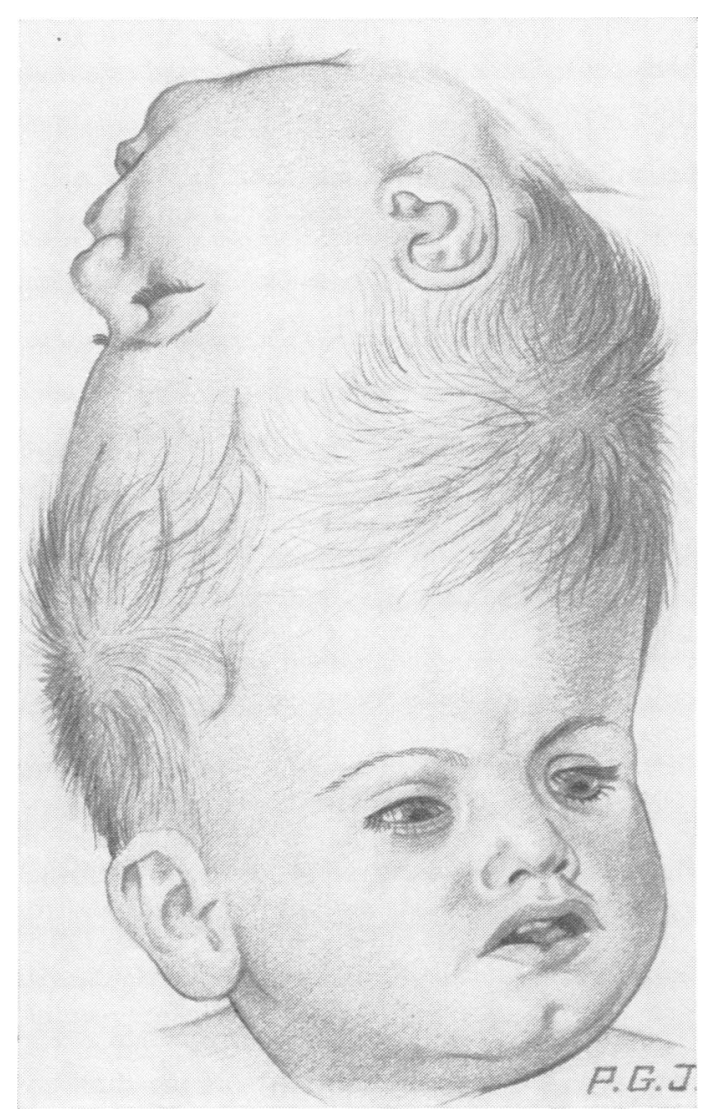

FIG. 4 Total craniopagus: type III.

conjoined skull, the long axis of one head being rotated relative to that of the other through an angle of $140^{\circ}$ or more (Fig. 3). In the third variety (type III), the angle of rotation of the long axis of one head on that of the other is intermediate between that in the other types (Fig. 4). As will be shown later, these differences of type are of considerable importance insofar as the deformity of the brains and abnormality of their circulation are concerned.

If it be decided that an attempt to separate the twins should be made, it is essential that a very thorough investigation of intracranial anatomy be carried out, since unless the operation is planned on the basis of such knowledge, it will almost certainly fail completely. The most informative investigation is carotid angiography, which provides knowledge of the relationship of the cerebra to the cranium, deformity of the cerebra, and the cerebral vascular circulation. This has been described by O'Connell (1964) and O'Connell (1968). In the past, until such investigations had been made, no picture of the intracranial anatomy could be developed. Now, however, examination of our material suggests that it may be possible from clinical examination to gain a picture of the intracranial abnormalities to be expected; thus one might predict the relationship of the cerebra to the cranium and the nature and presence of cerebral deformity. The type of vascular circulatory abnormalityespecially venous ones-that is present might also be suggested. With this in mind, the anatomy of total vertical craniopagus will now be reviewed in some detail.

\section{Abnormalities associated with total vertical craniopagus and mechanism of their production}

1. SCALP As a result of the junction, scalp at the vertex never develops. If separation is effected, it is clear that an enormous defect of scalp over the whole vertex of the head will result.

2. SKULL a. Vault There is no vault to either skull. The frontal, parietal, and occipital bones of each twin, which would normally provide this, articulate with one another around the equator of the common cranium. As in the case of the scalp, after separation is achieved there is left a large skull defect, the whole vault being absent.

b. Base While clinical examination reveals no obvious abnormality here, at postmortem examination well-marked abnormalities may be found. The first example (Fig. 5) is the skull base of one of the pair of twins (type I) illustrated in Fig. 2. These were not seen during life but colleagues provided the opportunity of making a postmortem examination. The drawing shows that the skull is extremely wide anteriorly with its maximum transverse measurement at the level of the anterior clinoid processes. Posteriorly, the petrous temporal bones give the impression of having been rotated medially around their apices so that the posterior fossa is small as also is the tentorium cerebelli, though its foramen is greatly enlarged. The anterior and middle fossae are capacious and the posterior cranium is small, the impression being one of a pear-shaped skull base. The other skull base illustrated (Fig. 6) is that of the fatality in the third pair operated upon (type III: Fig. 4). There is gross asymmetry; the posterior margins of the lesser sphenoidal wings make an 


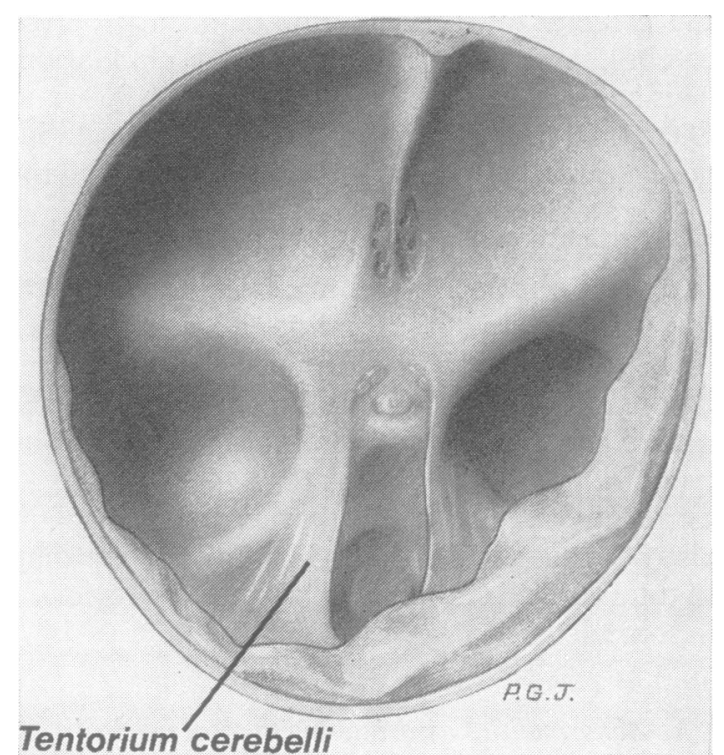

FIG. 5 Base of skull: type I craniopagus.

oblique line passing posteriorly when followed from left to right. The left anterior and middle fossae are capacious and separated by a shallow sphenoidal wing; those on the right are markedly smaller, though the temporal fossa is deep. The petrous temporal bone on the right is displaced posteriorly and

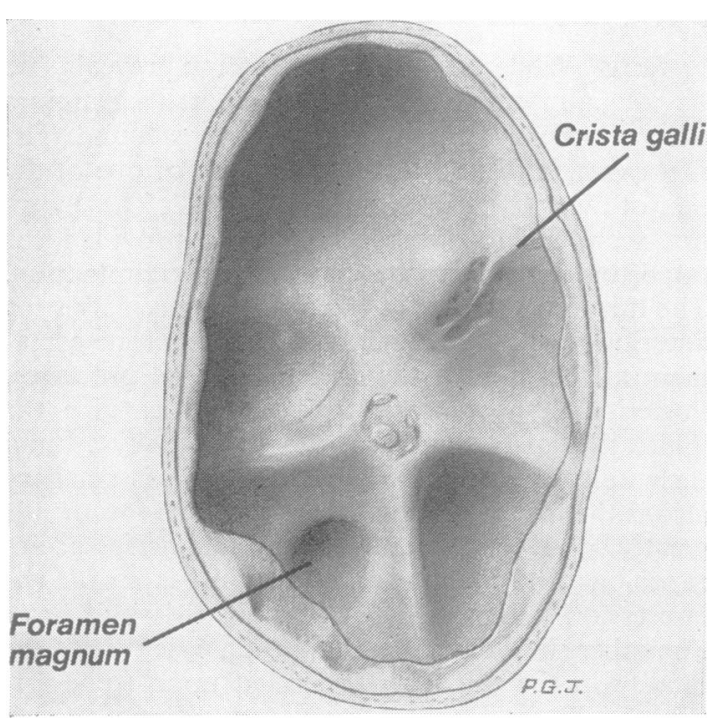

FIG. 6 Base of skull: type III craniopagus. medially so that the posterior fossa is small on this side. The skull base of the operative fatality in the other pair of type III craniopagus showed essentially similar changes to those just described. There has been no opportunity for postmortem examination of the skull base in type II cases (Fig. 3).

What is the cause of these deformations of the skull base? It is believed that they are related to the growth of the telencephalic vesicles. These diverticula of the prosencephalic cavity of the embryo appear during the fifth week of development. In relationship to their prosencephalic site or origin they grow anteriorly, superiorly, and posteriorly, coming in this manner to cover in succession the diencephalon, mesencephalon, and upper metencephalon. Development inferiorly is less marked but the vesicles grow medially to come into contact with one another in the midline above the neural tube. The wall of each vesicle thickens and, as its surface area increases, it is thrown into the characteristic convolutions of the cerebrum. The force developed by this growth process is considerable. Thus, between the fifth and 17 th weeks the brain as a whole increases in size 3000 times; in the same period the proportion of brain weight of the cerebral vesicles to that of the whole brain increases from $7 \%$ to $90 \%$; the thickness of the wall of the cerebral vesicle increases from $1 \mathrm{~mm}$ to $20 \mathrm{~mm}$ (Hamilton and Mossman, 1972). The effect of such cerebral growth forces on the skull base can best be considered when the cerebral deformities occurring in these cases have been described. While such deformities of the skull base might appear to have no direct practical importance, it will be seen later that they help towards the understanding of the gross cerebral deformities which, by their presence, may greatly increase the technical difficulties of operations to separate these twins. Moreover, these deformities are predictable from their relationship to the different types of total vertical craniopagus.

3. CEREBRUM In cases of total vertical craniopagus the two cranial cavities communicate so freely that the brains exist within a common cranium. As a result, growth processes in one brain instead of simply producing skull enlargement give rise to deformation of the other brain and, of course, such deformation will be mutual. The development of the telencephalic vesicle anteriorly and its extension superiorly and posteriorly must mean that the deforming growth forces are maximal in relationship with the anterior part of each brain. The type of cerebral deformity which occurs depends upon the degree of rotation of one head on the other, this, of course, altering the relationships of the frontal portions of the two cerebra. As has been pointed out, three groups of cases can be differentiated; in 
type I the rotation of one head on the other is minimal and the faces are directed to the same side. In type II the rotation is maximal $\left(140-180^{\circ}\right)$ and the faces are directed to opposite sides. In type III the rotation is intermediate in degree between that in the other two types.

On the first group (type I: Fig. 2), the developing frontal portions of the four cerebral hemispheres are intimately related in the anterior part of the conjoined cranium. What are thought to be the relationships of the developing cerebra at the $27 \mathrm{~mm}, 60$-day stage are shown diagrammatically in Fig. 7. The brains illustrated are drawn from the reconstructions of Hochstetter. As a result of the area of union, posterior development of the cerebrum will be impaired. Development superiorly can occur anterior to the union but will be restricted by similar growth of the opposite twin's anterior cerebrum. As a result, the anterior cerebrum is enlarged in both its vertical and transverse measurements, while the posterior cerebrum is small; the anteroposterior measurement of the brain is reduced. The lateral view of such a brain is illustrated by Robertson (1953); a

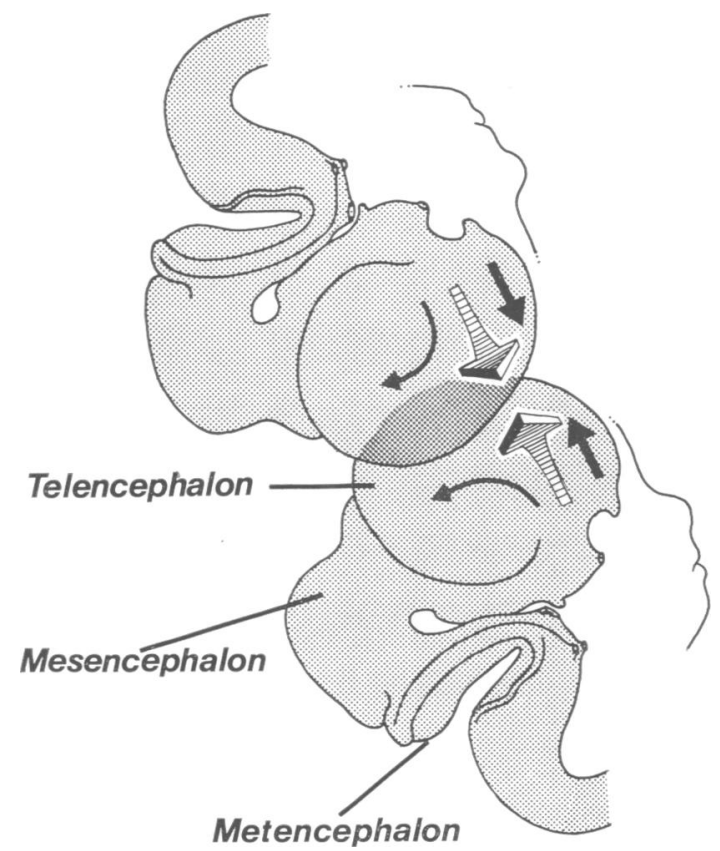

FIG. 7 Development of cerebral hemispheres in type I craniopagus. Arrows indicate direction and magnitude of growth forces. basal view is seen in Fig. 8-this drawing being one of the brains of the example of type I craniopagus personally examined post mortem. The cerebrum is short and wide with relative increase in the size of its anterior half. The skull base in this case is illustrated in Fig. 5. The deformity has already been described and is thought to be due to the increased size of the anterior cerebrum and stunted growth of its posterior portion. This leads to a widening and deepening of the anterior cranium and there is resulting stunting of its growth posteriorly (Fig. 7). The cerebral deformity in this type of total vertical craniopagus is illustrated in the diagrammatic drawing (Fig. 9).

In the second group (type II: Fig. 3), the faces are on opposite sides of the conjoined skull. What are thought to be the relationships of the developing cerebra again at the $27 \mathrm{~mm}, 60$-day stage, are shown diagrammatically in Fig. 10. As in the previous group, growth of the cerebrum posteriorly will be impeded but growth superiorly will be unopposed and the frontal portion of each cerebrum will tower upwards and perhaps make contact with the tentorium of its twin. The posterosuperior development of each cerebrum will be reduced since its growth will be impeded by that of the other twin's frontal cerebral area; each cerebrum will, in fact, be wedge shaped. The appearances are well demonstrated by carotid angiography in the case illustrated in Fig. 3. In Fig. 11 ( $a$ and $b)$ the left carotid angiogram of one

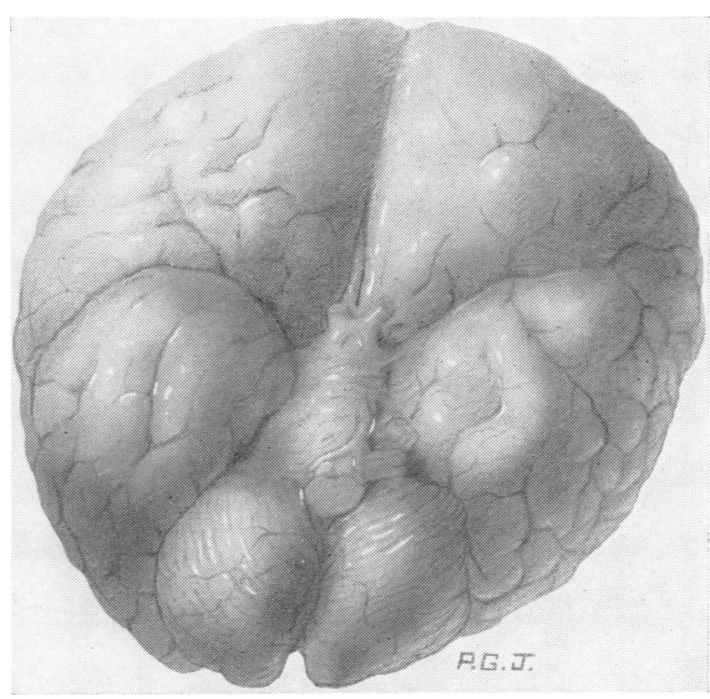

FIG. 8 Base of brain type I craniopagus. 


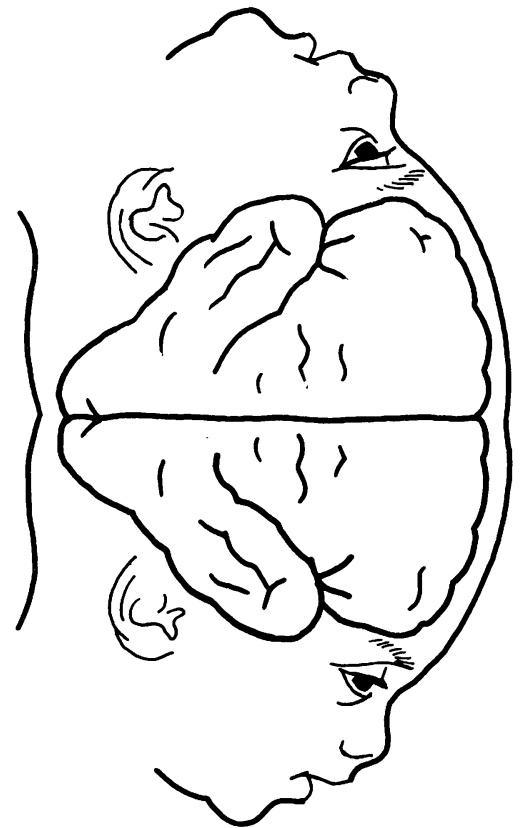

FIG. 9 Cerebral deformity in type I craniopagus.

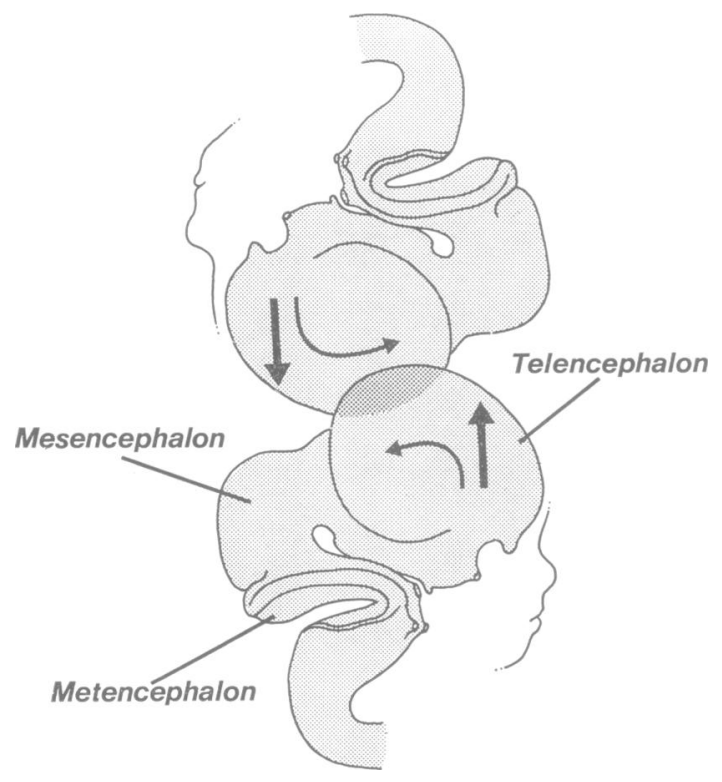

FIG. 10 Development of cerebral hemispheres in type II craniopagus. of the twins is seen in anteroposterior and lateral projections; in the capillary phase the frontal tower and wedge shaped hemisphere are demonstrated clearly. The other three hemispheres showed a similar deformity. As has been said, no postmortem examination of the skull base of such a type II craniopagus has been studied. Since the anterior portions of both cerebra are so early and fully decompressed, it might be expected that the bone changes would be less marked than in the other types. Figure 12 illustrates the cerebral deformity in this type of total craniopagus. In the third group (type III: Fig. 4), rotation of the heads is intermediate in degree between that in the other two types, and moreover since one vertex is, in a sense, placed across the other, it will overlap one side of the other head. This is illustrated in Fig. 4, where it will be seen that the frontal region of each child is set on the right side of the other's vertex. It is believed that the early development of the anterior cerebral region on the right side of the other twin's right cerebral hemisphere will cause the latter to be displaced to the left side of the cranium, the left cerebral hemisphere being compressed beneath it. The right frontal lobe will tower upwards as in the previous group and the left one will be overlapped by it. The appearances are best demonstrated again by means of carotid angiograms made in the first of the two pairs of such twins investigated in this way before separation. In Fig. 13 ( $a$ and $b$ ) anteroposterior and lateral angiograms after left carotid injection show the greatly compressed left cerebral hemisphere. In Fig. 14 (a and b), similar projections after right carotid injection are shown. The frontal tower is clearly seen in the lateral projection and the overlap of the left by the right hemisphere in the anteroposterior one. A diagrammatic drawing of the cerebral deformity in such type III cases is shown in Fig. 15.

The skull base associated with this type of brain deformity is seen in Fig. 6. The cerebrum of each child was displaced to the left across the skull base, the right hemisphere compressing the left one beneath it. This would explain the very large left anterior and middle fossae and the small right fossae. The deep right temporal fossa with medial displacement of the petrous temporal bone might be explained as resulting from pressure from the child's own right temporal lobe with the addition of the right frontal tower of the opposite twin.

It is thought that these observations explain the different types of cerebral deformity which occur in total craniopagus and suggest the reasons for the differences, and also that they explain the associated deformities of the cranial base. It thus appears that, in the four examples of total vertical craniopagus studied, their classification into three groups provides 

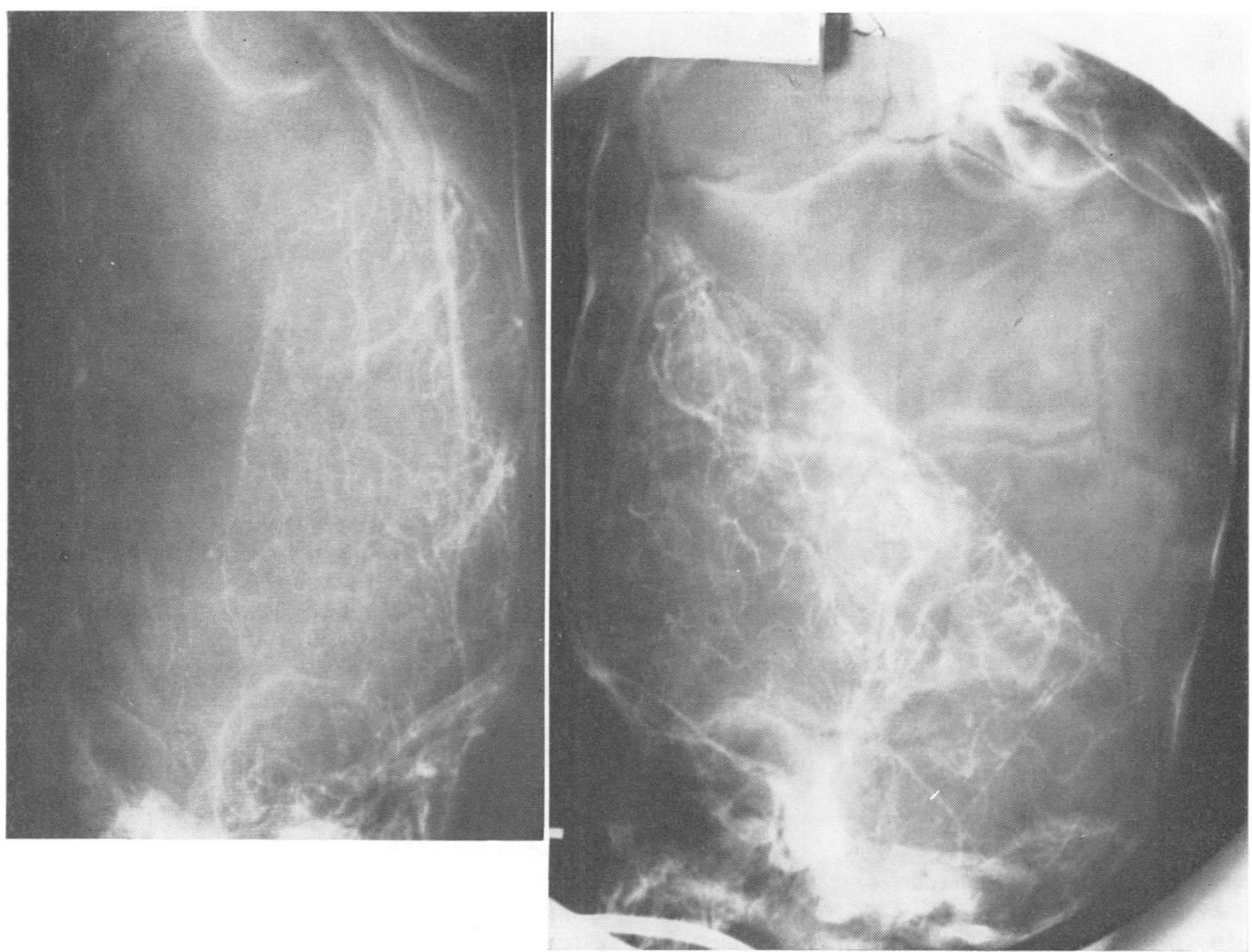

(a)

(b)

FIG. 11 Left carotid angiogram: type II craniopagus: (a) anteroposterior, (b) lateral.

the basis for an explanation of the different deformities of the cerebrum and cranium which have been found. The classification and explanation also appear applicable to certain cases described in the literature -for example, Barbosa (1949), Robertson (1953), and Grossman et al. (1953). It may well apply to all cases but adequate information concerning these has not been available in such reports as have been seen. As has already been mentioned, in cases of extensive union in other situations than the vertical one, intrauterine forces may be responsible for producing angulation at a union which was at first a vertical one.

4. MENINGes a. Pachymeninges In the three personally treated cases of total vertical craniopagus described above, as well as the further case examined post mortem, no layer of dura mater separated the two brains. It must be supposed that the ectomeninx which gives rise to the dura mater and cranium is absent from the area of contact between the cerebra, and dura mater is absent here as, of course, is the skull. In two of the cases a peripheral dural shelf, $10-15 \mathrm{~mm}$ wide, projected into the line of contact between the two brains and contained important vessels in its base. A similar fold was present on one side only in the third treated pair: small folds representing the falces cerebri and joined at their bases were present on the opposite side. In some of the cases described in the literature in which the faces were directed to the same side (type I), a thin dural septum extended between the related hemispheres, of one side only, to the midline. The falx cerebri was vestigial in all cases; the vestiges were basal and anterior, apart from those in the case mentioned above, in which-on one side only-small folds 


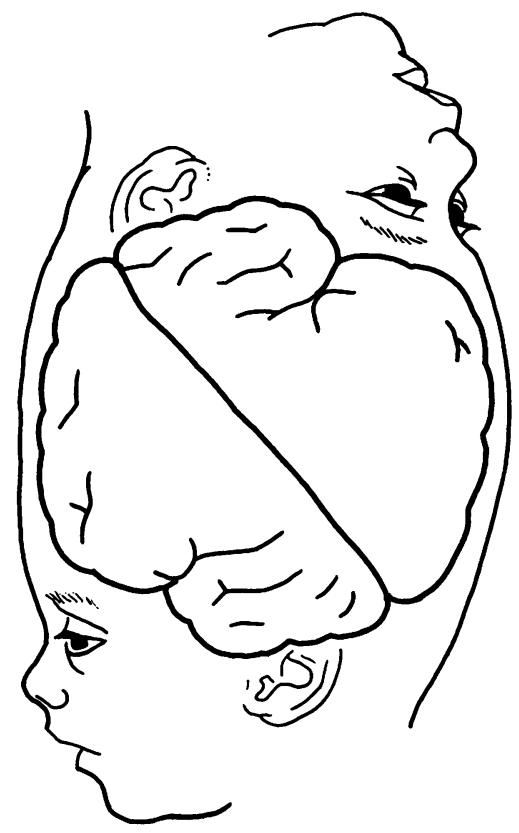

FIG. 12 Cerebral deformity in type II craniopagus.

representing the falces cerebri and fused at their bases, were present.

In considering the dural deficiency, it must be recalled that this is not only a defect at the area of contact between the cerebra; it includes the absence of hypoplasia of the falx cerebri and at times the deformity of the tentorium cerebelli already referred to. As far as the falx cerebri is concerned, since the portion of the primitive meningeal layer which gives rise to the dura mater over the surface of the apposed cerebra is lacking, there is no possibility of a falx developing here. Minor projections of dura mater between the hemispheres may be seen in basal regions not directly involved in the union. This was the state of affairs in all the personally examined cases. Around the periphery of the cranium a narrow circumferential fold of dura mater projects for a short distance between the two cerebra. This indeed would represent the falx cerebri in such cases projecting between the two brains instead of the two hemispheres of one brain. The tentorium cerebelliunrelated to the defect-is in its normal position. However, as has been seen, it may be hypoplastic and its opening considerably enlarged. Such changes may well be secondary to the absence of the falx cerebri which normally holds the centre of the tentorium superiorly and anteriorly; limitation of the development of the cerebrum posteriorly might also contribute to the tentorial deficiency.

b. Leptomeninges During the separation of the apposed brains, it appeared that the interdigitating gyri were, for the most part, covered by normal pia-arachnoid mater. However, in two of the cases, these layers appeared to be absent in some small areas and cerebral continuity appeared to be present here. It had previously been noted that arterial anastomoses were present in these areas. In Fig. 17a a large arterial anastomosis between a branch of the injected twin's middle cerebral artery and an artery in her sister's brain is seen, as well as a smaller one more posteriorly. A possible explanation for these findings will be suggested later.

5. VASCULAR CIRCULATION The cerebral vascular architecture in craniopagus can be clearly demonstrated by carotid angiography (Du Boulay, 1964). The most important angiographic findings from the circulatory viewpoint will now be considered with reference to the first two pairs of twins coming under our care; these will be described and related to the operative findings.

In Fig. 16a and $b$ the arterial and venous phases of a left carotid angiogram in one of the first pair of twins treated (type II) is seen. The arteriogram (a) reveals normal but displaced arteries, the anterior cerebral artery and its branches coursing superiorly to supply the frontal tower. The middle cerebral artery and its branches are also displaced anteriorly and superiorly - these changes indicating the deformity of the hemispheres already discussed (Fig. 12 and Fig. 11, a and b). Of greater importance from the circulatory aspect is the phlebogram (b). A group of large veins converge on a vascular channel which passes along what proved at operation to be the line of contact of the cerebra around the periphery of the junction. The united vessels then discharge into the other twin's transverse sinus. There is but little evidence of venous drainage into the injected child's own transverse sinus. The peripheral venous channel proved at operation to be a circumferential sinus in the base of the narrow medially projecting dural fold which could be regarded as a representative of the falx cerebri but lying between the cerebra of the two children instead of between the hemispheres of each one's cerebrum. It was noted that the dura mater in relationship with this sinus contained large venous channels between its layers. Surprisingly, connections between veins on the cerebra themselves and the sinus over the greater part of its length were inconspicuous, as were arachnoid adhesions to it. The major drainage of blood from the exposed areas of cerebrum was 


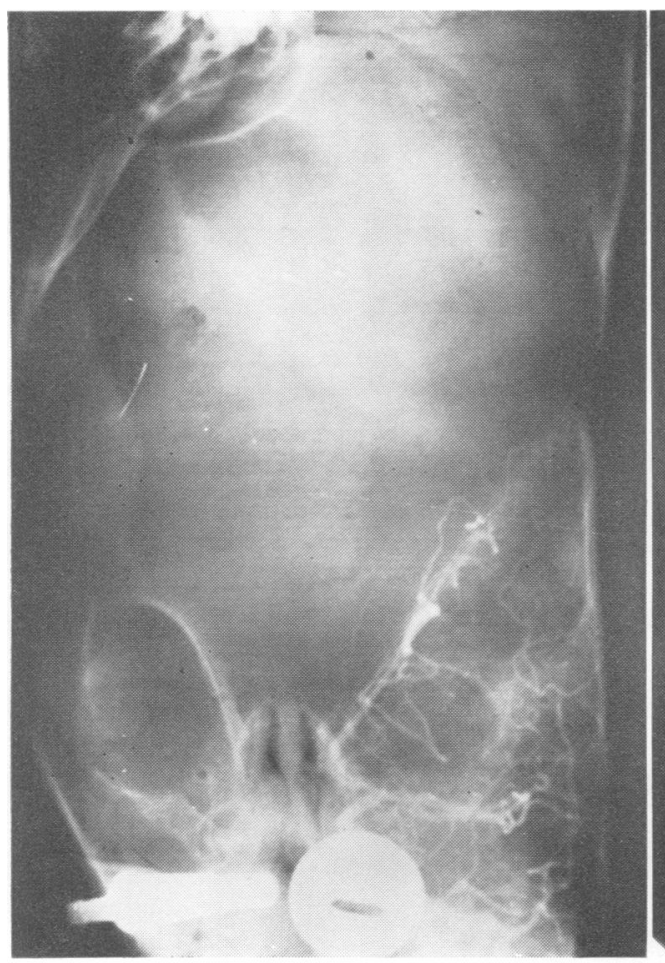

(a)

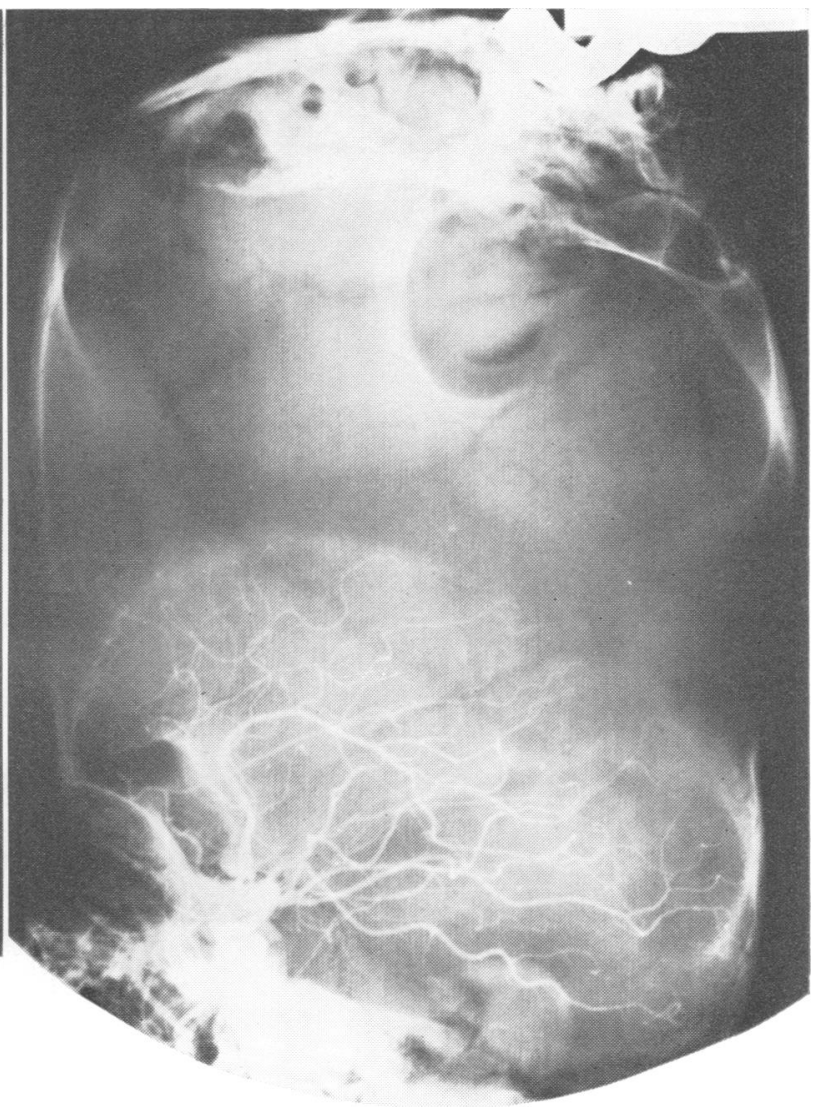

(b)

FIG. 13 Left carotid angiogram: type III craniopagus: (a) anteroposterior, (b) lateral.

thus through a group of large veins passing directly anteriorly to empty into the lateral sinus of the other twin either through or independently of the circumferential sinus. In addition, in the midline between the two cerebra there were some small posteriorly directed veins passing through a lake of cerebrospinal fluid, in the direction of each child's own lateral sinus. Investigation of the other twin of this pair by carotid angiography revealed an exactly similar venous abnormality.

Figure 17 ( $a$ and $b$ ) are angiograms from the second pair of twins dealt with (type III). The arteriogram (a) is right-sided and shows the upward stretching of the anterior and middle cerebral arteries occasioned by the shape of the cerebral hemisphere. This arteriogram also demonstrates arterial anastomoses between the branches of the two children's middle cerebral arteries-a large central and a smaller posterior one. The phlebogram (b) is leftsided; as discussed under cerebral deformity, this hemisphere is compressed and overlain by the right one and its outline suggests a normal shape. Again frontal veins converge on a circumferential vein at the line of apposition of the two left hemispheres, and the greater part of the flow is into the opposite twin's transverse sinus.

When the investigation of the first pair of twins revealed this crossed venous drainage, it seemed that there could be little hope of separation without obstructing the venous return from both children's cerebra. Indeed, the possibility of venous grafting was considered and preparations for it made preoperatively. However, when exploration was carried out it was found that instead of a superior sagittal sinus between each child's cerebral hemispheres there was a circumferential venous sinus between the 

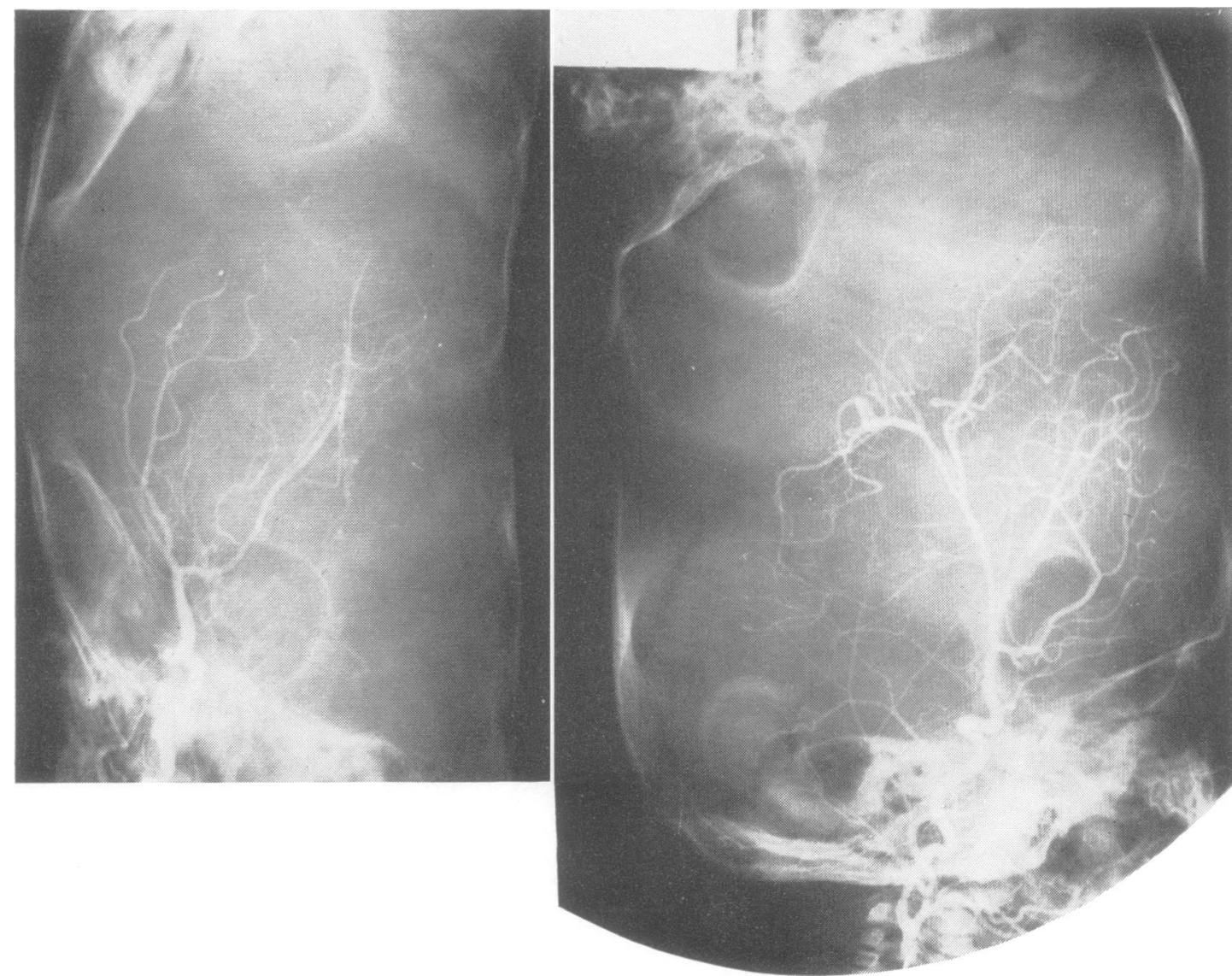

(a)

(b)

FIG. 14 Right carotid angiogram: type III craniopagus: (a) anteroposterior, (b) lateral.

two brains along the line of their contact and lying within a small medially projecting dural fold. It was further found that venous drainage from the cerebrum to which this fold was given was normally maintained but severe venous infarction occurred in the brain of the other child. The anatomy of the peripheral sinus is indicated diagrammatically in Fig. 18.

No example of the third variety of total vertical craniopagus (type I), that in which the faces are turned to the same side, has been encountered clinically, so that the clear picture of the vasculature which can be achieved by carotid angiography was not obtained, but a postmortem examination was carried out on one such pair (Fig. 2). As the heads were separated during the examination, no peripheral venous sinus nor any dural fold at the line of contact of the cerebra was seen. Neither was there any dural layer between the brains nor any falx. Between the hemispheres of both children there was vascular pia mater possibly containing veins. Related to the conjoined occipital areas of the cerebra, a venous lake was seen but its detailed anatomy was not studied. In the example of this type of union treated by Grossman et al. (1953) a dural septum separated the cerebral hemispheres on one side of the junction; three longitudinal veins passed posteriorly in relationship with it. However, the anatomy of these cerebral veins at their union with the two pairs of lateral sinuses was confused and occasioned difficulty which was probably responsible for the death of one child soon after operation. Thus in these (type I) cases, although the positioning of the heads which predisposes to crossed venous circulation is absent, 


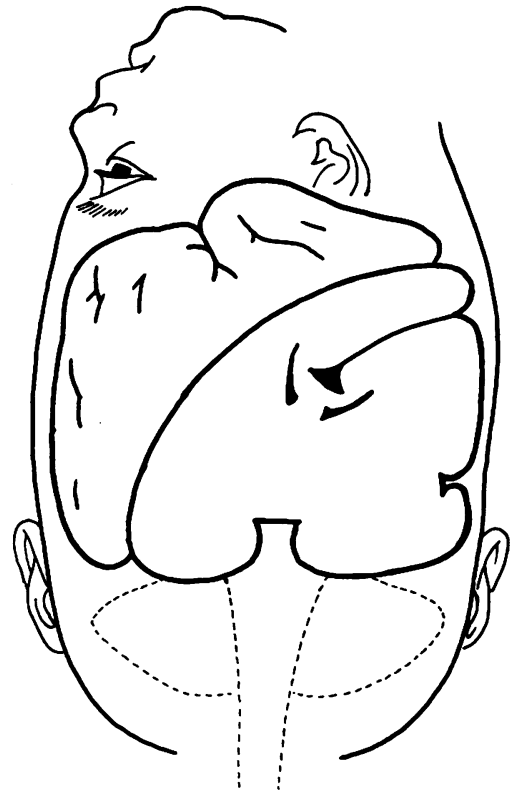

FIG. 15 Cerebral deformity in type III craniopagus.

the close relationship between veins draining the cerebra of both twins in the area of the torcular appears to make separation and the survival of both a difficult goal to achieve.

In considering the basis of the abnormalities in the venous drainage of the cerebra, one can do no better than recall the statement of Streeter (1918) on the development of the vascular system of the brain:

'The development of the blood vessels of the head... demonstrates the important embryological principle of what may be termed integrative development.... The vascular apparatus does not, independently of itself, unfold into the adult pattern. On the contrary, it reacts continuously in a most sensitive way to factors of its environment, the pattern in the adult being the result of the series of the environmental influences which played upon it during the embryonic period.'

The normal superior sagittal sinus arises from a plexus of veins which is situated in the sagittal plane between the developing cerebra. This venous plexus lies in a well-marked layer of embryonic tissue (ectomeninx) which later forms the dura mater, that portion between the cerebral hemispheres giving rise to the falx cerebri and that between cerebrum and cerebellum to the tentorium cerebelli, the two being continuous beneath the posterior cerebrum. As the cerebrum develops superiorly and posteriorly, the ectomeninx develops with it and an extension of the venous plexus is carried posteriorly within it. This plexus is continuous with another similar one in the embryonic tissue between the cerebrum and cerebellum from which the lateral sinus will develop. Thus, with the growth posteriorly of the developing cerebral hemispheres, the falx cerebri with the sinuses within it is developed progressively from before backwards. All the veins from the superior part of the lateral surface of the cerebrum drain into this superior sagittal sinus. The sinus drains into the transverse sinus lying in the membrane between cerebrum and cerebellum. This is the residuum of the three dural plexuses which drained into the internal jugular vein. With the growth of the cerebrum posteriorly, it is tilted in the same direction through $90^{\circ}$ to gain the position of the adult lateral sinus, the portion distal to the bend becoming the sigmoid sinus. As a result of the same posterior development of the cerebrum the ectomeninx between it and the cerebellum is compressed to form the tentorium cerebelli. In total vertical craniopagus there is no ectomeninx at the site of union and no development of skull, dura mater, or falx cerebri can occur in an area which is rapidly increasing in extent as a result of cerebral development. There can, therefore, be no sagittal venous plexus and a superior (or inferior) sagittal sinus cannot develop. However, at the line of apposition of the cerebral hemispheres of each child, a shallow infolding of the ectomeninx occurs between the brains, and contains a plexus in its base, formed by venous tributaries from each brain. This represents the superior sagittal sinus but is instead a circumferential one. Anteriorly and posteriorly, it joins the lateral sinuses of the twins. As the cerebra grow, the venous ring of the circumferential sinus will grow with them. The great anterosuperior development of the twins' frontal cerebral areas will occasion a similar displacement of the sinus. The relationship of each twin's frontal tower to the opposite twin's tentorium will result in the enlargement and drainage of the major superior cerebral veins into the anterior part of the circumferential sinus or the tentorial plexus (lateral sinus) itself. Thus, much of the venous drainage of each child's cerebrum, which would normally be carried posteriorly through its superior sagittal sinus to its own lateral sinus, is in this manner directed into its twin's sinuses and heart. The remainder of the superficial venous drainage of the cerebra must be by way of the Sylvian and inferior cerebral veins. In the third variety of craniopagus in which crossed venous circulation does not occur superior sagittal veins have been found. These discharge into each twin's own lateral sinuses. No superior sagittal sinuses are present, however, and it appears that the arrangement of veins at the tentorium may be complex. 


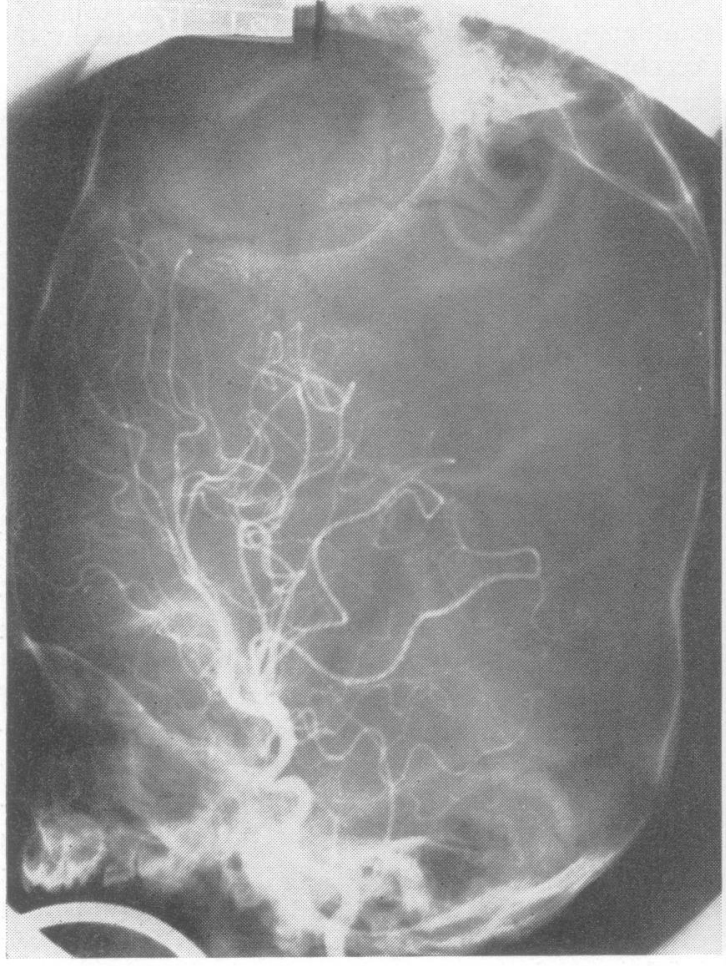

(a)

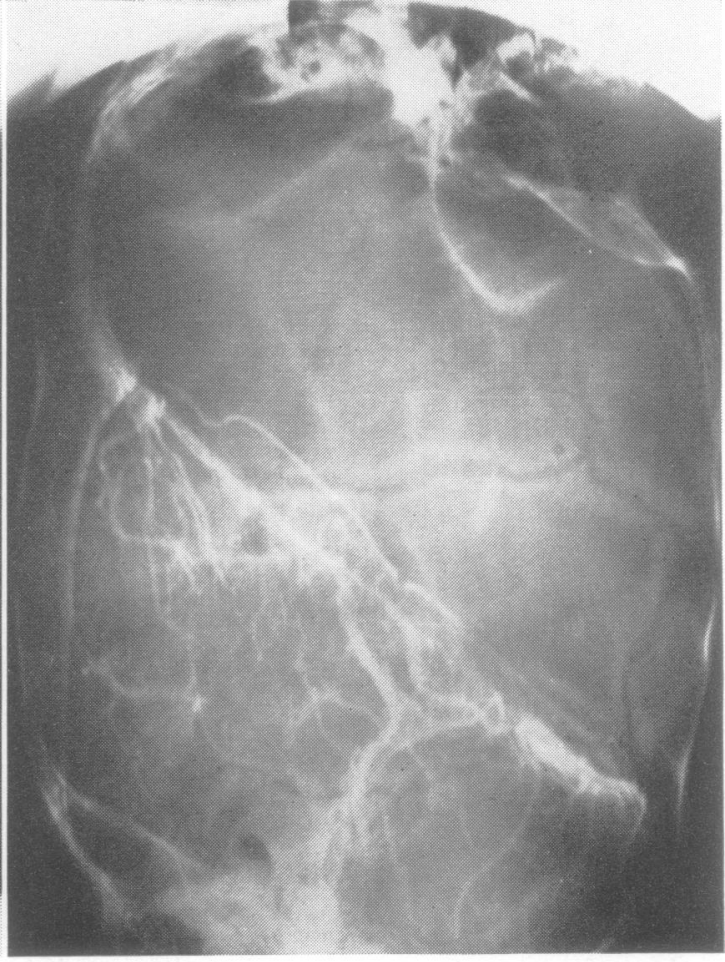

(b)

FIG. 16 Left carotid angiogram: circulation in type II craniopagus: (a) arteriogram, (b) phlebogram.

6. CEREBROSPINAL FLUID CIRCULATION In considering the problems which might result from an attempt at separation of craniopagus twins, that of the maintenance of the cerebrospinal fluid circulation arises. While arachnoid villi occur in relationship with many of the intracranial venous sinuses, normally they are most conspicuous in relationship with the superior longitudinal sinus and its lacunae. These villi are present at birth or even earlier and by the age of 3 years hypertrophic villi (arachnoid granulations) may be numerous in the sinus (Clark, 1920). When investigation shows an absence of the sinus, one is left wondering how the loss of this large area of cerebrospinal fluid absorption can be compensated for. Would separation be followed by a cerebrospinal fluid fistula or would a communicating hydrocephalus develop? During the separation of the first pair of twins, a lake of cerebrospinal fluid was found between the cerebra over the shallow vertically compressed longitudinal cerebral fissures. In each case, a longitudinal vein draining blood from both cerebral hemispheres passed posteriorly through this lake to the torcular region. There was little adhesion between the circumferential dural shelf and its contained sinuses and the cerebral coverings. It thus appeared to be a channel connecting the infants' lateral sinuses and receiving much of the blood from their cerebral hemispheres. The site of major cerebrospinal fluid absorption was not exposed. Since arachnoid villi project through the dura mater into sinuses rather than into veins unclothed by dura mater, it must be supposed that the sinuses concerned were basal ones-lateral, cavernous, petrosal, sphenoparietal, etc. At all events, although in all cases a transient leak of cerebrospinal fluid occurred postoperatively, this ceased after a short period and no defect of cerebrospinal fluid circulation has shown itself in subsequent years.

\section{Prognostic and therapeutic implications of abnormalities}

The significance of the various abnormalities des- 


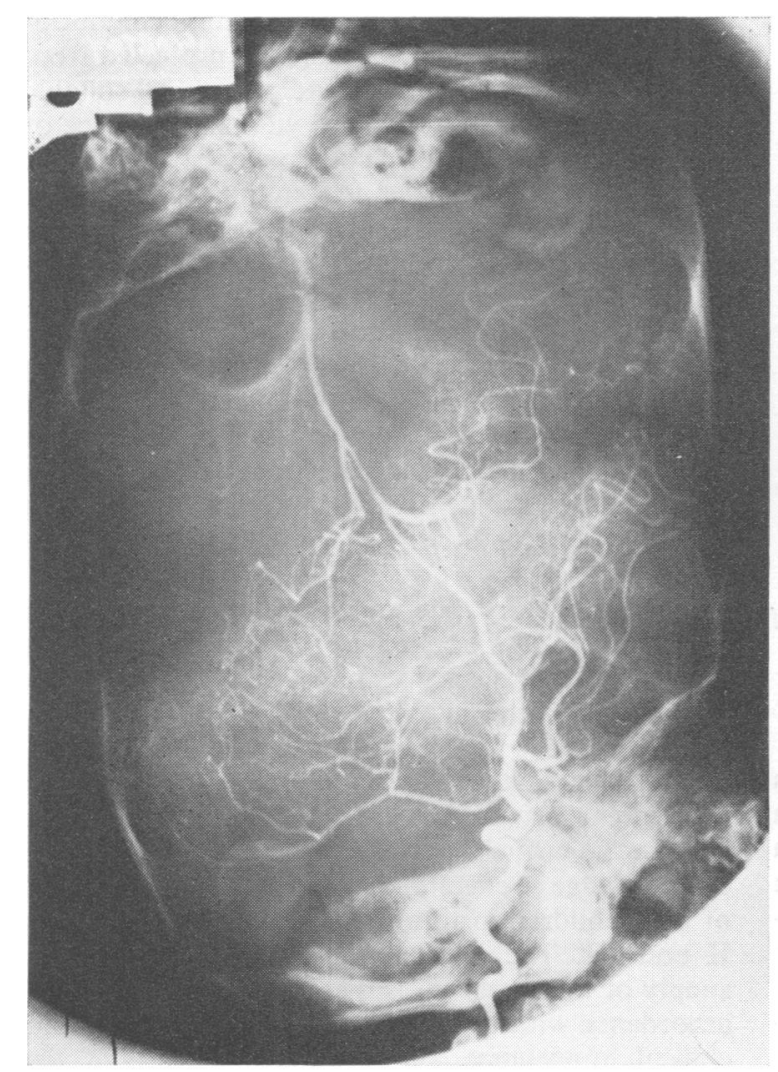

(a)

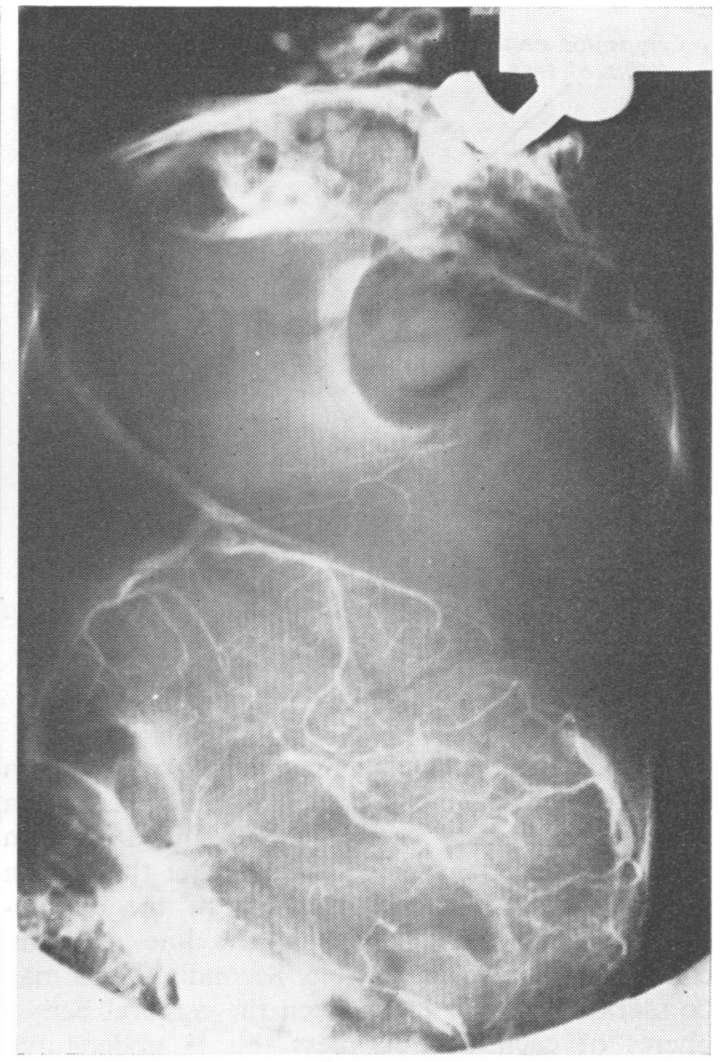

(b)

FIG. 17 Bilateral carotid angiograms: circulation in type III craniopagus: (a) right arteriogram (showing anastomotic vessels), (b) Left phlebogram.

cribed is revealed in their description. However, it may clarify certain points if they are considered individually under the heading of their prognostic and therapeutic relevance.

1. SCALP In the personal cases the large scalp defect was skilfully overcome by plastic surgery (Jayes, 1964). Rotation flaps were utilized and the donor areas covered with split skin grafts. When skilled plastic surgery is available, the problem of scalp closure does not affect prognosis or treatment.

2. SKULL a. Vault The vault of the skull is absent and an enormous skull defect exists after separation. It has been considered that no attempt to close this defect at the time of separation could be justified; it would add to the difficulty of scalp replacement over the brain and might predispose to infection. Indeed, in each of the surviving children it has been thought that a delayed cranioplasty was best avoided and an external prosthesis has been provided (Fig. 19, a and b). When the plastic hat is combined with a wig some of the disadvantages of this form of protection are diminished.

b. Skull base The deformity does not of itself affect prognosis or treatment. Were it to be discerned in skull radiographs, it would simply point to the cerebral deformities which give rise to it.

3. CEREBRUM In each of the three types of total vertical craniopagus which have been described, well-marked deformity of the cerebrum was present and differed according to the degree of rotation of one head on the other. Recognition of such deformity is essential before any attempt at surgical separation 


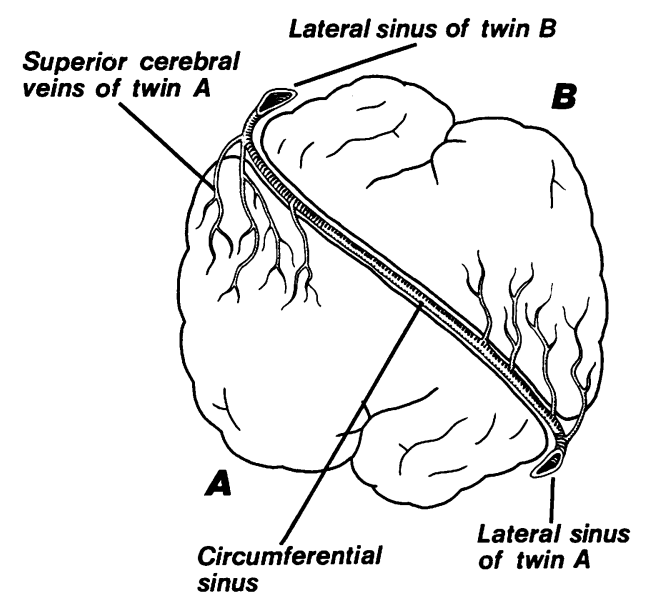

FIG. 18 Anatomy of peripheral dural shelf and circumferential sinus.

is made. In the first place, it will frequently mean that the line of contact between the cerebra is not on an equatorial plane through the conjoined cranium but a very different one. It is essential that, when separation is attempted, the line of the circumferential scalp incision follow the line of brain contact as closely as possible. Secondly, there may be marked asymmetry between the cerebral hemispheres of each child. Unless this is understood, considerable difficulty may arise during the separation and injury to the cerebrum in one or both children may occur, in the false belief that cerebral fusion is present.

4. MENinges a. Pachymeninges The most obvious abnormality here is the large dural defect over the whole of what would normally be the cranial vault when separation is effected. This was present in all of the personally treated cases but from the literature it appears that occasionally a thin dural layer is found to separate one hemisphere of one child from the related one of the other child. In each of the three surviving cases, reconstituted freezedried dura mater was sutured into the defect and was of greatest value forming an excellent protection for the cerebrum. Bearing in mind the very large area of the defect, it must be realized that it would be extremely difficult to find in either child a sheet of tissue of adequate size and structure to close the dural gap. The other abnormality of the dura mater was the absence or hypoplasia of the falx cerebri. The reason for this has been suggested. Its importance lies in the fact that the superior sagittal sinus is absent. Although some longitudinal veins may be seen in the longitudinal cerebral fissure, being intradural, they are abnormal, being less protected from pressure changes and not providing a vessel suitable for the reception of arachnoid villi. The absence of the falx cerebri has other consequences. In the first place, there is no barrier to cerebral displacement across the midline such as the falx provides between normal hemicrania. This may explain the gross displacement of cerebrum seen in type III craniopagus. Secondly, the dural partition between the posterior fossa and the rest of the cranium, the tentorium cerebelli, may be flat instead of normally tented and hypoplastic with considerable enlargement of its foramen. The fact that it is unsupported by the falx cerebri in the midline may well be in part responsible for these abnormalities.

b. Leptomeninges No important abnormality was seen but the arachnoid may have been absent in some small areas and fusion of the cerebral tissue may possibly have occurred here.

5. VASCULAR CIRCULATION The abnormalities here have great prognostic importance and no doubt explain the virtual impossibility in the present state of knowledge of effecting separation with the survival of both children in total vertical craniopagus, types II and III. The only abnormality of the arterial supply of the cerebrum is displacement of vessels in accordance with the ccrebral deformity; this has no clinical importance. However, in the case of the venous drainage the changes have the highest importance. The superior sagittal sinus will be absent in both twins in most cases and be replaced (in types II and III craniopagus) by a circumferential sinus which unites the lateral sinuses in the two children. The relationship of this sinus to the cerebra has been described above: it can carry blood posteriorly to its own lateral sinus from the large group of superior cerebral veins which in each twin discharge into the opposite twin's lateral sinuses. If these veins leaving the frontal tower are ligatured between the circumferential sinus and the second child's lateral sinus and if the complete circumferential sinus is now donated to the first child, cerebral venous drainage in that child remains intact. However, in the case of the second child when the same group of veins is ligatured between its frontal pole and the circumferential and lateral sinuses, venous infarction of its cerebrum results. This has been the state of affairs in each of the three pairs personally operated upon. Indeed, in the third pair of twins treated, it was discovered at angiography that the venous ring of the circumferential sinus included the central portions of both lateral sinuses of each twin. In order to maintain the integrity of the ring it was necessary to 

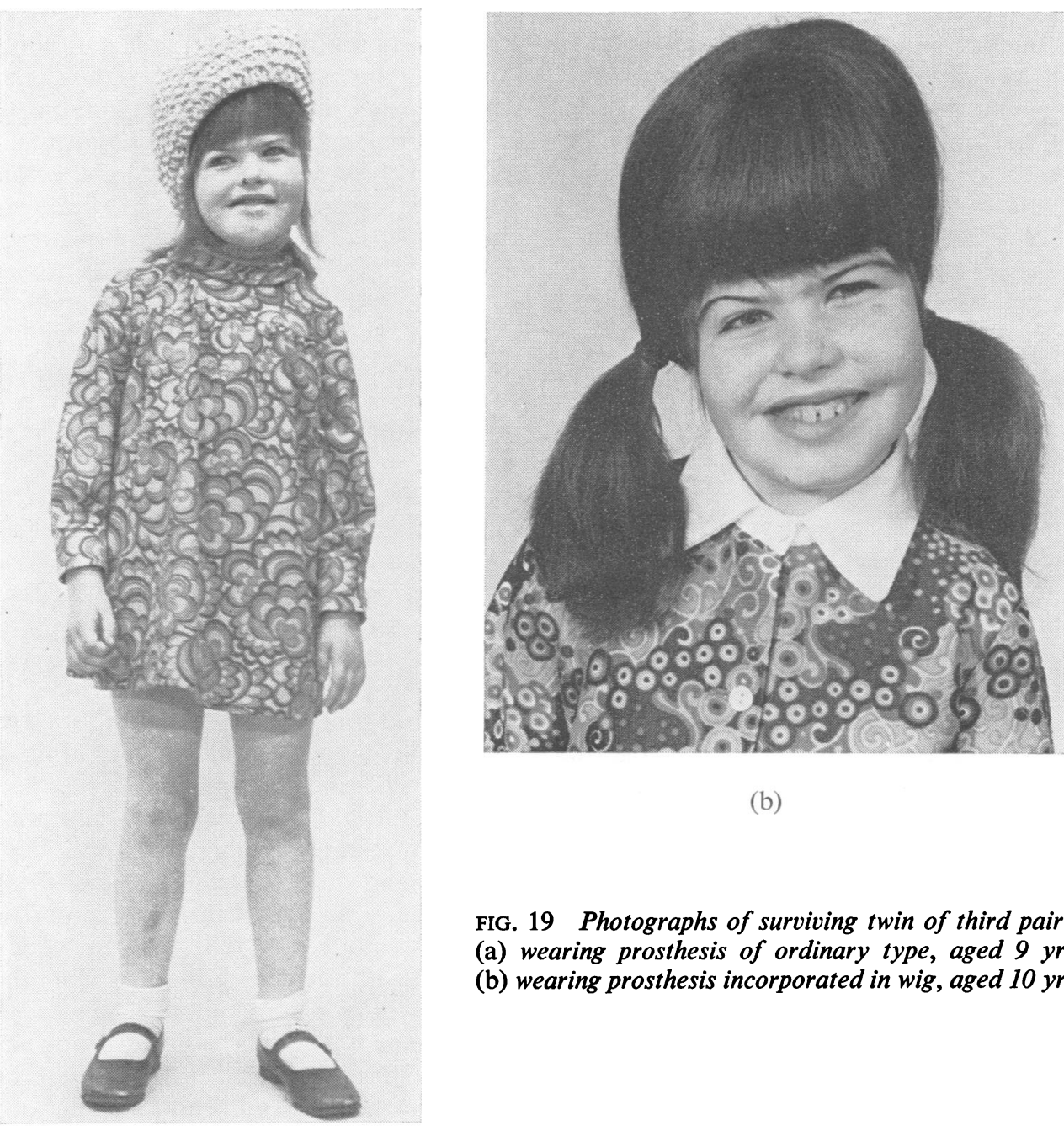

(b)

FIG. 19 Photographs of surviving twin of third pair:

(a) wearing prosthesis of ordinary type, aged $9 \mathrm{yr}$,

(b) wearing prosthesis incorporated in wig, aged $10 \mathrm{yr}$.

(a)

donate these portions of these sinuses of one child to the other. In the first type of craniopagus (Fig. 4), in which a crossed venous circulation is not present, difficulty with cerebral venous drainage still arises. There is no superior sagittal sinus and the longitudinal veins in its place may terminate posteriorly in a venous lake. In the single report of surgical treament of such a case (Grossman et al., 1953), the technical difficulties experienced in dealing with this venous abnormality apparently led to the deterioration and early death of one child.

6. CEREBROSPINAL FLUID CIRCULATION No ab- normality of this has been noted in the personal series of cases. The absence of a superior sagittal sinus as described above implies that other, probably basal, sinuses replace this important vessel where normally a concentration of villi return cerebrospinal fluid to the bloodstream.

\section{DISCUSSION}

Before attempting to describe the essential congenital defect in craniopagus twins, it may be helpful to refer to some generally accepted modern embryological views. As in normal 
monozygotic twins so in craniopagus twins genetic factors influence the occurrence. In addition, animal experiments suggest that environmental factors which slow the development of the embryo may play a part in the development of both separate and joined monovular twins. It is now believed that conjoined twins develop as a result of incomplete fission of a single developing embryo and not fusion of separate embryos. It is further believed that the abnormality is established at the end of the second week of development (Benirschke and Kim, 1973). This implies that, when the junction is established, the anterior neuropore is still present. It closes at the 26th day, its site being subsequently indicated by the lamina terminalis. The telencephalic vesicles appear at the 25th day and, before this, the cutaneous ectoderm is separated from the neural tube by a mesodermal layer, the meninx primitiva (Hamilton and Mossman, 1972). This layer splits into an inner one, the endomeninx which forms the piaarachnoid membrane, and an external one, the ectomeninx, which forms the dura mater and skull. As the growing telencephalic vesicles meet in this tissue, they gain a leptomeningeal covering from it but in total vertical craniopagus no ectomeninx separates them. As a result, no development of a cranial vault with its dural lining is possible.

From the study of the material described, it is believed that the congenital defect in total vertical craniopagus is an area of absence of cutaneous ectoderm (scalp) and ectomeninx (skull and dura mater) at the site of the union. Around the margins of the defect the scalp, skull, and dura mater of one child are fused with those of the other. The absence of dura mater at the vault leads to a failure of development of the falx cerebri and possibly an abnormality of the tentorium cerebelli; more important, it means that the superior sagittal sinus cannot develop and a gross abnormality of cerebral venous drainage results. All the remaining abnormalities result from mechanical pressure: these include deformity of the skull base, cerebral deformity and displacement, leptomeningeal defects, and areas of cerebral fusion. In addition, it is possible that cerebral dysfunction may be produced by this pressure. The abnormalities of the skull base and cerebrum in the three types of total vertical craniopagus have been described above and an explanation for them put forward. The other abnormalities will be considered, after a brief further reference to partial craniopagus.

In partial craniopagus the congenital defect again involves ectoderm (scalp) and ectomeninx (skull and dura mater). The superficial extent of the involvement is limited, however; it is frequently no more than a few centimetres in diameter, although at times the area is more extensive. More important is the depth of the involvement. At times only the cranial portion of the ectomeninx is involved with a simple junction of crania and normal dura mater; or the dura mater of one child may be adherent to that of the other through the cranial defect; or a larger or smaller defect of the dura mater within the cranial defect permits contact of one child's pia-arachnoid membrane with that of the other. The growth of one brain in no way interferes with that of the other and there are no forces at work to prevent the development of the falx cerebri and superior sagittal sinus, or to produce the serious venous circulatory abnormality seen in total vertical craniopagus. As has been said above, partial craniopagus is essentially an extracranial abnormality.

Returning now to the discussion of total craniopagus, in separating the cerebra of the twins it is noticeable that they are very closely apposed with interdigitating gyri. For the most part a layer of pia-arachnoid mater covers each hemisphere but in places it may appear to be absent. In these small areas actual cerebral continuity between one child and the other has been thought to be present. In considering the possible cause of these areas of leptomeningeal defect and brain junction, their extent is so limited relative to the size of the junction that they cannot be regarded as part of the congenital defect itself, in existence since the second week of development. It seems possible that pressure might again provide the explanation. Normally, the arachnoid mater over the superior surface of the cerebral hemispheres is in contact with the smooth dura mater lining the skull vault and will slide on it with the cerebral pulsations. In cases of craniopagus, the arachnoid covered hemispheres subject one another to a continuous and pulsating pressure. Forces of pressure and friction could thus be active at the site of contact. 
It is possible that these forces could produce minor tears in the serous membrane and the related cerebral cortex and that vascular adhesions could unite the brains in such areas.

It is possible that the anatomical disturbances listed can be explained by pressure giving rise to brain displacement, deformity, and compression as well as small areas of meningeal atrophy with superficial cerebral contusions. It is also possible that compression could occasion physiological disturbance. Thus psychological testing of these infants has been carried out during the months before the separation operations when the necessary investigations were in progress. During the latter part of this period it has been found that performance falls below that appropriate to the child's age (Franklin, 1964; Udall, 1975, personal communication). It had been supposed that this was simply the result of restricted mobility with consequent inability of each child to respond normally to visual and auditory stimuli. The disadvantageous position from the psychological point of view is clear but is this the sole factor?

In the first year of life the weight of the brain increases by $135 \%$, growing therefore as rapidly as it had done in utero. Does the fact that the whole of the superior and part of the superolateral surface of the cerebrum is in contact with another cerebrum instead of the dural lined cranium interfere with growth at this critical period? The displacement and deformity of the cerebra which have been described, are such as to mould the skull base and it is probable that the cerebrum itself is subject to compression. If this be so, it is obvious that, if separation is to be attempted, it should be carried out with minimal delay. However, a thorough preoperative investigation remains essential if any measure of success is to be achieved.

It has been seen that partial craniopagus must be clearly distinguished from the total form; in the absence of other serious abnormality, separation will always be indicated in the former group and there is an excellent prospect of survival of both twins of each pair to lead normal lives. Separation in cases of total vertical craniopagus presents very great problems and the observations on three personal cases set out above describe an attempt to understand these and solve them. Some problems-for example, the maintenance of the cerebrospinal fluid circulation-have no foundation. Others-scalp closure, repair of the dural defect and protection of the cerebrum in the absence of the cranial vault - can be solved. Understanding of the deformities of the skull and brain has, it is believed, been achieved and this can be helpful during an attempt at separation. The abnormality of cerebral venous drainage has been demonstrated and its embryological basis suggested. The importance of the circumferential venous sinus in those cases with a crossed venous drainage (types II and III) has been indicated, and this knowledge makes possible preservation of the circulation through one brain. However, it has not been found possible to ensure the venous drainage of the second child's cerebrum and consequently separation has only achieved one survivor. As has been seen, before the first separation operation, preparations for the insertion of a vein graft from the frontal veins of each child to its lateral sinus had been made but the discovery of the circumferential sinus was thought to make a graft unnecessary. Possibly this could be considered for the second child - that is, that without the circumferential dural fold and its contained veins-in future operations, but the technical difficulties would be great. Or it might be found possible to give half the circumferential sinus to one child and half to the other. A careful postmortem study of twins with total vertical craniopagus in whom no attempt at separation had been made could demonstrate the exact relationship of the circumferential to the lateral sinuses and show if such a sharing could be achieved. Anatomists have long described the superior and inferior anastomotic cerebral veins. These connect the superficial middle cerebral vein, which drains into the cavernous sinus, to the superior sagittal sinus superiorly and the lateral sinus inferiorly. Such veins may be multiple in the adult and even more numerous in the fetus (O'Connell, 1934). It might be hoped that, in the absence of the superior sagittal sinus, blood might be drained inferiorly through these anastomotic veins. However, it seems clear that the distortion of the cerebral hemispheres with anterosuperior projection of the frontal poles in each child carries much of the venous drainage with it to its twin's lateral sinus. The problem has not 
been solved but recognition of a problem can be a step towards its solution. Such recognition has resulted from the investigation and treatment of this personal series and it is hoped that this work will provide other neurosurgeons with some landmarks on the map of a largely uncharted territory and lead to better results.

The final great problem is the ethical one in the treatment of total vertical craniopagus. Of the three pairs of such twins dealt with personally, in the first one child died six months after operation and his brother survives aged 17 years, without any gross neurological defect but retarded. Of the second pair, one died during surgery and the other when aged 6 years, being severely mentally deficient. Of the third pair, one again died during operation and the other now aged 12 years, is an active, happy child with a marked left hemiparesis.

The early fatality in each case resulted from the cerebral venous circulatory impairment in this twin of the pair explained above-and no solution to this problem has so far been discovered. Can it then be justified to embark upon a separation operation when death of one of the children seems inevitable? Before attempting to answer this question the possibilities which exist for such children and their parents should be carefully considered. It must be stressed again that apart from the union, which is a superficial one of scalp, skull, and dura mater, these infants may appear entirely normal, developing normally from all points of view during the early months after their birth. Indeed, there are reports of such children being cared for at home by their mothers at this stage. The children are in no sense monsters but the situation occasioned by the junction is a monstrous one.

It must be recalled that the embryonic duplications which result from the splitting of a single fertilized ovum are of several types. When the results of the splitting are free and symmetrical, identical twins result; but if asymmetrical, only one twin is normal and the other (acardius) depends upon it for its circulation. When the twins are joined they too may be symmetrical and each component a complete individual; this is the group of which craniopagus is a variety; the other members of it differ in the site of the junction. When the components are symmetrical and each less than a complete individual-for example, bifurcation of the cranial or caudal end of the products of development - the term 'double monster' can appropriately be used and, of course, there is no possibility of surgical treatment here. When the joined twins are unequal, one is a parasite within or on the surface of the other. It will be seen that the present paper deals with the types of conjoined twins in which the components are symmetrical and each a complete individual.

There are three possible courses open to those faced with the problem of total vertical craniopagus. Firstly, the twins may be allowed to die at birth; secondly, they may be allowed to develop in their united state; or, thirdly, an attempt may be made to separate them.

As far as the first possibility is concerned, it must be stressed that these infants can, apart from their union, with proper postnatal care develop into attractive babies. There is no question of unwarranted enthusiastic and energetic measures being required to ensure their survival. Those who criticize attempts at $\frac{\rho}{\Phi}$ separation do so on the grounds that this is a $\bar{\alpha} \vec{c}$ misguided attempt to secure the survival of the unfit; they consider that the children should be allowed to die at birth. Such a view may seem rational in the abstract; it is a different matter when the surgeon is presented with the real life problem. Partial craniopagus should always be treated surgically and with good prospects of saving both children to lead normal lives. In total vertical craniopagus, with the knowledge which has now accumulated, it is clear that one child has a prospect of survival after surgery. This will make the suggestion that both be allowed to die unacceptable to many. While at the present time the survivor is left with defects, the possibility of a worthwhile life exists for it. It is to be expected that improvements in technique will diminish these defects and, indeed, in time may make the survival of both children a possibility.

The second possibility-permitting the twins to develop in their united state-derserves more careful consideration. This course has been followed in the past with survival of the twins into adult life. The union thus may constitute no threat to existence but what is the quality of life of those so united? Much of it must be passed in the horizontal position with strict limitations as to the amount of possible rotation 
to either side. Some examples of type I craniopagus have been trained to stand and walk but with obvious difficulties and for limited periods; in types II and III these difficulties would clearly be increased. Such children can learn but the limitations on the ability of each adequately to explore its environment and respond normally to stimuli of various types brings about an early falling behind for their age group in the performance of psychological tests. Moreover, it is believed that each of the brains in the common cranium, by displacing, compressing, and deforming one another, contributes to defective intellectual development. Detailed reports of the condition of such surviving twins are rarely published. A recent one (Todorov et al., 1974) described 24 year old craniopagus twins (type I). These showed gross intellectual retardation and education was virtually impossible. Such abandonment of the twins to their appalling bondage is not, of course, in any sense a treatment; indeed, it ignores the fact that on physical grounds alone the union itself will lead to continued deterioration of intellect, at least for some years after birth. The third possibility is to attempt surgical separation, and this is a major undertaking. A thorough investigation to review the intracranial anatomy in both twins will require many months for its completion and during this period every effort must be made to overcome the physical and psychological handicaps which the union can produce. The surgical procedure is a prolonged one, involving a large team. The measure of success achieved has been small-one long-term survivor from each pair and all with defects, neurological or intellectual. The early fatality after each operation resulted from cerebral venous circulatory impairment in this twin of the pair. No solution for this problem has been found in types II and III craniopagus, though possibly this disturbance of circulation may be less likely in type I cases; however, no such case has been dealt with personally. In the present state of knowledge, then, surgical separation of the twins entails sacrifice of one child in the hope of achieving survival and a better life for the other. The decision to operate is thus a difficult and even agonizing one. Of course there must be full discussion of the problem between the parents and the physicians concerned and there must be complete agreement as to the proper course to take; this will almost invariably be in favour of operation. However, it is for the surgeon himself to decide upon what is for him the right course in each case. The justification for such an operation lies in the knowledge that in postnatal life the union retards intellectual development by the limitation it places on mobility and on the other activities of the developing child. Moreover, the disturbance of highest brain function is contributed to by the compression and displacement of each child's brain by that of its twin, one brain acting as a tumour in its relationship with the other. To break the union and prevent this progressive deterioration at the earliest possible time is a proper course of action. If, as is true up to the present time, there is only one survivor, the gain for this child can be great in terms of quality of life and it justifies the loss of the twin, since the survival of the pair in the united state offers little more than existence to both.

I am much indebted to the Department of Medical Illustration of St. Bartholomew's Hospital for the very numerous photographs of our material which were essential to this review of our experience. Several of the drawings are based on these photographs and I am grateful to Mr Peter Jack of the Department for the care he has given to this work as well as to his other drawings.

\section{REFERENCES}

Baldwin, M., and Dekaban, A. (1958). The surgical separation of Siamese twins conjoined by the heads (cephalopagus frontalis) followed by normal development. Journal of Neurology, Neurosurgery, and Psychiatry, 21, 195-202.

Barbosa, A. (1949). Tentative surgery in a case of craniopagus. Revista Brasileira de Cirurgia, 18, 1047-1050.

Benirschke, K., and Kim, C. K. (1973). Multiple pregnancy. New England Journal of Medicine, 1276-1284 and 13291336.

Clark, W. E. (1920). On the Pacchionian bodies. Journal of Anatomy, 55, 40-48.

Du Boulay, G. H. (1964). Radiological examination of two pairs of craniopagus twins. British Medical Journal, 1, 1339-1341.

Franklin, A. W. (1964). Paediatric care of craniopagus twins. British Medical Journal, 1, 1342-1344.

Grossman, H. J., Sugar, O., Greeley, P. W., and Sadove, M. S. (1953). Surgical separation in craniopagus. Journal of the American Medical Association, 153, 201-207.

Hamilton, W. J., and Mossman, H. W. (1972). Human Embryology, p. 478 and p. 533, 4th edn. Heffer: Cambridge.

Jayes, P. H. (1964). Plastic repair after separation of craniopagus twins. British Medical Journal, 1, 1144-1146.

Klar, E. (1963). Zur Trennung der Cranioencephalopagen. Archiv für Klinische Chirurgie, 304, 883-889. 
O'Connell, J. E. A. (1934). Some observations on the cerebral veins. Brain, 57, 484-503.

O'Connell, J. E. A. (1964). Investigation and treatment of craniopagus twins. British Medical Journal, 1, 1333-1338.

O'Connell, J. E. A. (1968). An operation to separate craniopagus twins. British Journal of Surgery, 55, 841-850.

Potter, E. L. (1961). Pathology of the Foetus and Infant, 2nd edn. Year Book Publishers: Chicago.

Robertson, E. G. (1953). Craniopagus parietalis. Archices of Neurology and Psychiatry (Chic.), 70, 189-205.

Sapinski, W. (1966). A case of craniopagus. Wiadomości Lekarskie, 19, 1733-1734.
Streeter, G. H. (1918). The developmental alterations of the vascular system of the brain of the human embryo. Embryology, no. 24. Carnegie Institute: Washington.

Todorov, A. G., Cohen, K. L., Spilotro, V., and Landau, E. (1974). Craniopagus twins. Journal of Neurology, Neurosurgery, and Psychiatry, 37, 1291-1298.

Voris, H. C., Slaughter, W. B., Christian, J. R., and Cayia, E. R. (1957). Successful separation of craniopagus twins. Journal of Neurosurgery, 14, 548-560.

Wolfowitz, J., Kerr, E. M., Leven, S. E., Walker, D. H., and Wetten, K. B. (1968). Separation of craniopagus twins. South African Medical Journal, 42, 412-424. 